\title{
Correlation between Vitalism and Genetics According to the Paradigm of Complexity
}

\author{
Marcus Zulian Teixeira ${ }^{1}$ \\ ${ }^{1}$ School of Medicine, University of São Paulo, São Paulo, Brazil \\ Homeopathy 2020;109:30-36.
}

\begin{abstract}
Address for correspondence Marcus Zulian Teixeira, MD, PhD, Hospital das Clínicas da FMUSP, Departamento de Ginecologia e Obstetrícia, Av. Dr. Enéas de Carvalho Aguiar, 255, $10^{\circ}$ andar, sala 10.166, 05403-000, São Paulo/SP, Brazil

(e-mail: mzulian@usp.br; marcus@homeozulian.med.br).
\end{abstract}

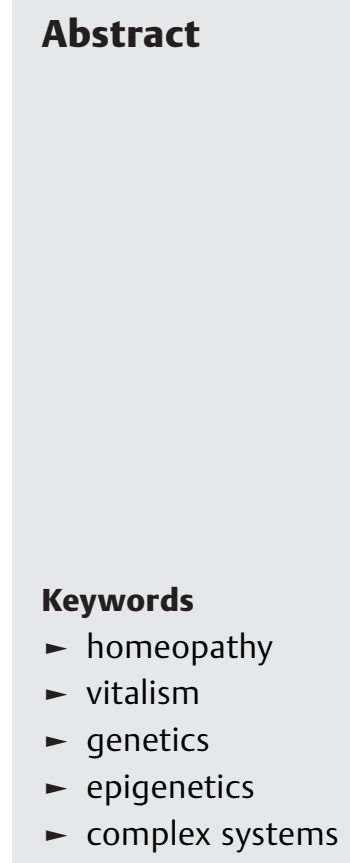

Background In homeopathic philosophy, vital force is a non-material substrate that is responsible for maintaining the body's sensations and functions and where homeopathic medicines act. In genetics, the body's vital functions are controlled by biochemical information, which is contained in the cell genome and consists of a protein encoding portion (exome) and another that regulates this encoding scheme (epigenome). Both the philosophical vital force and the genome present properties of complex and dynamic self-organisation systems.

Aims This study aimed to explore and develop a philosophical-scientific correlation between vitalism and genetics according to the complexity paradigm.

Results Vital principle and genome present inseparable composition among distinct existing components that influence one another and form a network of connections that create complex and dynamic self-organisation behaviour. Described in both models, 'vortex' indicates the existence of a force coming from within the system that is externalised as an emergent, information-transmitting phenomenon. Supporting this correlation, some experimental studies show that homeopathic medicines act on the genome by modulating gene expression.

Conclusions In line with the similarity of existing characteristics and properties, the genome may be considered as hypothetical biological substrate of organic vital force.

\section{Introduction}

In addition to the four scientific pillars (therapeutic similitude, homeopathic pathogenetic trials, prescription of potentised and individualised medicines), which support homeopathic therapeutic practice, homeopathic philosophy uses the vitalist concept and miasmatic theory to broaden the understanding of the health-disease process and infer a non-material representation or substrate that justifies the action of ultra-highly diluted medicines (at concentration values beyond the Avogadro limit).

The hypothetical homeopathic vital force is substantially linked to the physical body (organic vital force) and is responsible for preserving the state of health and maintain- ing life. Vital imbalance brings physical illnesses and, by restoring the balance, the body returns to a state of health. As a result of its dynamic and non-material nature, the vital principle is influenced by other types of energies or related forces, such as the subtle manifestations of the psyche and those of the mind. Since the potentised homeopathic medicine has a similar nature, it is able to restore vital harmony, as long as it is used according to the therapeutic similitude principle (curative vital reaction). The irrational vital force differs in nature and kind from the intelligent spirit, which is defined as an autonomous entity that is apart from the inseparable physical-vital unity. Hahnemann did not delve deeply into understanding the vital force's nature or essence, received

March 24, 2019

accepted after revision

April 23, 2019

published online

July 18,2019
DOI https://doi.org/

10.1055/s-0039-1692162. ISSN $1475-4916$.
Copyright $\odot 2020$ The Faculty of Homeopathy
License terms

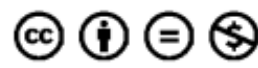


despite regarding it as the prima causa morbi of diseases. The homeopathic vitalism presents a set of aspects that is similar to that of other medical and philosophical concepts. ${ }^{1-5}$

In homeopathic miasmatic theory, which addresses the nature of chronic diseases, Hahnemann adds the existence of three chronic miasms (psora, sycosis, and syphillis) of dynamic nature to their etio-pathogenesis (causam morborum chronicum), by attributing them the prerogative of being the main obstacle to the action of correctly prescribed homeopathic medicines, thus preventing the curative vital reaction from occurring. 6

Studies conducted on complex and dynamic self-organisation systems, which were employed in biomedicine to broaden the understanding of homeostatic physiological mechanisms, can be used in homeopathy to justify the modus operandi of the vital principle, since both phenomena present similar properties (non-linearity, self-organisation and dynamism, among others).

In the field of genetics, studies describe a non-coding portion of the genome (epigenome) that controls the encoding portion (exome) following a complex, dynamic and selforganisation behaviour, thus allowing the production of countless types of proteins that are responsible for preserving the state of health and maintaining life. Thus, similar to the vital principle, the cell genome (exome plus epigenome) is continuously modulated throughout life, according to the external and internal influences affecting the individual, activating or silencing the genes that are responsible for the manifestation of physiological disturbances or diseases.

The current study aims to explore and describe the philosophical-scientific correlation between vitalism and genetics according to the paradigm of complexity, which transcends the polarisation between holism and reductionism, vitalism and materialism, and helps broaden the understanding of the disease process described by the homeopathic model and the hypothesis researchers have raised that the cell genome can be considered as the biological representation or substrate of organic vital force.

\section{Hahnemann's Vitalist Concept}

The author has been studying homeopathic vitalism since $1996,{ }^{2-5}$ aiming at broadening the understanding of the aspects that permeate the human disease mechanism, the cure of diseases, and the action of highly diluted medicines.

According to Hahnemann's vitalist concept, ${ }^{1-5}$ the homeopathic vital force is similar to the Hippocratic vis medicatrix naturae, automatically and instinctively activated and subjected to the laws of the physical body.

Throughout life, the vital force is substantially linked to the physical body (inseparable physical-vital unit or organic vital force), thus making it possible for the body to have sensations, perform its functions and display self-preservation abilities. When the vital force or principle, which maintains the state of health and preserves life, fails to perform its dynamic activity, the body gets sick or dies. According to the homeopathic vitalist concept, every disease is caused by the imbalance in the organic vital force, as a result of a dynamic influence of a disease-promoting agent (internal and/or external 'morbific agents'). In turn, healing and the return to a state of health occur by restoring balance or the integrity of the vital principle (Organon der Heilkunst, 6th ed., paragraphs 10-16). ${ }^{1}$

However, despite grounding the health-disease homeopathic concept on the modus operandi of the vital force, Hahnemann did not work to understand its nature, to move away from the 'futility of transcendental speculations', repeatedly stating in his body of work that there is no need to know 'the internal essence of the disease', 'the non-material essence that produces the disease, the vital force' or understand 'how the vital force causes the organism to display morbid phenomena, that is, how it produces disease', so that they can be cured. He suggests that, rather than looking for the 'prima causa morbi in the hidden interior of the organism', the healer must stick to 'the sensible and manifest representation of the disease': in other words, to the signs and symptoms that the patient presents as the main goal of healing (Organon, Introduction, paragraphs 6-13 ${ }^{1}$; The Chronic Diseases, Preface to fourth volume). ${ }^{6}$

By this strictly clinical and experimental approach, where vital force disturbance is reflected outwardly by the manifested signs and symptoms, the homeopathic physician conducts the diagnosis and chooses the homeopathic medicine that causes similar manifestations in healthy experimenters (Organon, paragraph 7$)^{1}$ Thus, by producing an artificial disease that is very similar to the natural one, the homeopathic medicine acts by triggering a reaction from the vital principle against the pre-existing organic disturbance, removing the signs and symptoms manifested by means of the principle of symptomatic therapeutic similitude (Organon, paragraphs 21-25). ${ }^{1}$

Accordingly, homeopathic medicine, which is prepared following a pharmaco-technical process of dynamisation (that acts by 'dematerialising the matter itself'; Organon, paragraph 269), ${ }^{1}$ can restore health and harmony to the vital principle, since it possesses 'non-material (dynamic, virtual) modifier forces' of similar nature to that of the vital force (Organon, paragraphs 11,16$){ }^{1}$ By keeping the same previous position of avoiding the deeper comprehension of the inner nature of the vital force, Hahnemann re-states that 'the nonmaterial force hidden in the inner nature of medicines can in itself never be discovered by us by a mere effort of reason' (Organon, paragraph 20). ${ }^{1}$

Since it behaves like other types of related energies, Hahnemann compares the non-material force of homeopathic medicine with the dynamic force of mineral magnetism, electricity, galvanism, and electromagnetism (Organon, paragraphs 286, 287). ${ }^{1}$

According to the Hahnemannian vitalist anthropology, ${ }^{5}$ 'the instinctive, irrational, and unintelligent, but energetic automatic vital force' (Organon, Introduction) ${ }^{1}$ differs in nature and kind from the rational and intelligent spirit, which uses the physical-vital unit 'for the higher purpose of our existence' (Organon, paragraph 9). ${ }^{1}$ This spirit (soul) is differentiated from the vital principle as an autonomous entity. 
In addition to the spirit, Hahnemann adds to the human non-material nature the mind or psyche, 'invisible subtle organ of the mind' or 'almost non-material, mental, and emotional organs', entities that are responsible for mental and psychic manifestations (thoughts, emotions, and feelings), which influence the vital force, physical body, and health (Organon, paragraphs 215,216 ): ${ }^{1}$ hence the relevance that is attributed to mental and psychic aspects in the etiopathogenesis of diseases (Organon, paragraph 213). ${ }^{1}$

In short, we observe in the homeopathic vitalist concept a hierarchy of mutual influences among the several instances, in which the spirit manifests its potential by means of thoughts, emotions, and feelings that emanate from the mind (psyche), acting on the organic vital force and, consequently, on the health-disease process. ${ }^{2-5}$ However, since Hahnemann did not probe the essence of this organic vital force or how it causes diseases, he prepared an experimental treatment model based on the symptomatic externalisation of the vital disturbance.

By proposing to act on the prima causa morbi of diseases (vital dystonia) by means of its clinical representation (totality of signs and symptoms), Hahnemann shielded the homeopathic model from metaphysical speculations, thus valuing the postulates that could be corroborated according to the logical and scientific thinking of his time.

\section{Complex and Dynamic Self-Organisation Systems}

In recent years, the concepts of complexity and self-organisation have been the object of study in diverse science fields and were employed in broadening the understanding of how physical, biological, behavioural, social, political, economic and cultural systems work. A growing number of studies in the biomedicine field employ the complexity paradigm to extend understanding of the self-regulating homeostatic mechanisms of the many physiological systems and body components. ${ }^{7-9}$

Etymologically speaking, 'complexity' comes from the Latin word, complexus, which means 'that which is woven together', 'twisted together' or 'intertwined'. Thus, in any complex system, two or more distinct existing parts or components must be interconnected and form a stable structure. A complex system cannot be analysed or separated into a set of independent elements without being destroyed (a substantial and inseparable unit among parts). As a result of this, it is not feasible to employ reductionist methods to interpret or understand them. ${ }^{10,11}$

Complex and dynamic systems include countless simple behaviour units that influence one another in an intrinsic network of connections, thus creating a complex global behaviour. Such adaptive complex systems violate the classic principles of logic (determinism, reductionism, linear causality and continuity, among others), presenting specific characteristics and properties. Among them, the self-organisation property stands out - the one where the order/ disorder binomial emerges from the multiple interactions among component units, and there is the need for some mechanisms to pre-exist so that the phenomenon is manifested. Examples of those are: thermodynamic opening (energy flow through the system); non-linear, dynamic behaviour; local interaction; large numbers of independent components with distinct behaviours; occurrence of feedbacks and related emerging phenomena (domino effect, resonance, and vortex); organised global behaviour (meta balancing) and multi-scale effects, among others. ${ }^{10,11}$

According to Palazzo, ${ }^{10}$ the science of complexity transcends the 'polarisation between reductionism and holism, allowing the modelling of systems that simultaneously present the distinction and connection characteristics', a model that is observable in the mathematical and reversible concept of network, which consists of nodes and connections among them, thus allowing the parts to establish relationships among one another. While the connections are neglected in the reductionist approach, where only the nodes are valued, the holistic approach eliminates as many distinctions as possible among nodes, and values the connections only. Accordingly, both methods reduce a complex phenomenon to a simple representation, 'a loose set of differentiated nodes or a mass of connections among equal nodes', neglecting essential aspects of the phenomenon's characteristics.

\section{Correlation of Vitalism with the Paradigm of Complexity}

In the homeopathic scientific literature, the complex and dynamic system theory has been used to correlate the modus operandi of the homeopathic vital principle to self-regulating homeostatic mechanisms. ${ }^{12-15}$ Despite not clarifying the intrinsic nature of the organic vital force, this approach assists in understanding the dynamics of the vital principle's action by outlining analogies among concepts, characteristics and properties that are involved in the role it plays in maintaining the overall state of health.

By correlating the modus operandi of the homeopathic vital principle to the operational process of complex and dynamic systems, Bellavite ${ }^{13}$ highlights three essential properties that are common to both phenomena: non-linearity, self-organisation, and dynamism. To the assumption that the non-linearity of complex systems describing a random behaviour that is sensitive to small disturbances - which results in the absence of proportionality between first stimulus (input) and final outcome (output) - the authors correlate the assumption of therapeutic similitude, where a primary and direct action of an ultra-highly diluted homeopathic medicine (infinitesimal disturbance) triggers a secondary and inverse reaction (biphasic, hormonal, paradoxical or rebound effect) ${ }^{14}$ The magnitude of the effect of homeopathic high dilutions on the vital principle also counters the classic linearity, since growing vital reactions or therapeutic outcomes (outputs) are observed with reduced concentration of the doses (inputs). ${ }^{12,15}$

Self-organisation is complex systems' property of displaying unpredictable global behaviour patterns, as a result of the local interaction of its components. In homeopathy, selforganisation of the vital principle displays its behaviour pattern in the set of characteristic signs and symptoms manifested that represent the interaction among the vital manifestations of the many isolated physiological systems (network of 
connections creating the global complex behaviour). According to Bellavite: ${ }^{13}$ 'this notion of emergent properties of large numbers of interacting parts also allows a reasonable explanation of Hahnemann's 'vital force' in terms of total activity of all the cells in the body, of complex feedbacks and homeodynamics. It is a crucial aspect of the healing process that billions of cells act in concert to destroy foreign invaders or tumour cells and to re-establish the healthy morphological and functional state'. This homeostatic self-regulation of the complex physiological system (rebalancing of the vital principle) may be obtained by administrating an individualised homeopathic medicine or symptomatic simillimum 'that reproduces the whole symptom pattern of the ill state'. ${ }^{4}$

As a fundamental property of complex systems, dynamism represents the ability to change continuously in response to external and internal influences or stimuli, thus granting plasticity and self-organisation properties to the systems. According to its author, ${ }^{13}$ if this dynamism is clearly observed in the complexity of the etio-pathogenesis of diseases, and is the result of the influence of distinct factors (environmental, psycho-emotional, physiopathological and genetic, among others), it is also responsible for the complexity of the healing process, where multifactorial therapeutic action is needed for neutralising them. Concerning the homeopathic model, the dynamic vital principle disturbance is the result of distinct etio-pathogenetic factors that are represented in the manifestation of the characteristic symptomatic totality. In turn, vital rebalancing occurs by neutralising the set of these symptomatic manifestations.

Other correlations between the vitalist phenomenon and the properties of complex systems can also be outlined. According to Palazzo, ${ }^{10}$ the vital force is related to 'vortex', the emerging phenomenon that indicates the presence of a force that comes from within the system, the result of the very masses in circular motion that animate the phenomenon, experimentally evidenced in the cell membrane. ${ }^{16}$

'Whirlpools in troubled waters and tornadoes in turbulent skies are perfect examples of vortex. What is curious about vortex is that, in its centre, no force seems to exist [despite] sucking large masses from an undefined point. This, however, is just an illusion caused by the circular movement of the masses. If they are removed from the vortex, there will be nothing left. It is like removing all of an onion's layers expecting to find anything inside it. However, by observing the vortex, it is made clear that there is a force somewhere. Where is it? Perhaps the answer is one of the most important notions in the science of complexity: it comes from within the system. Even when an external force seems to be organising the vortex, the very masses in circular movement are the ones driving the phenomenon. ${ }^{, 10}$

According to Palazzo, ${ }^{10}$ this knowledge about the vortex phenomenon is important because it 'ended a long-time dispute between vitalism and materialism', by showing that both views are correct, according to the analysis framework: life's very existence depends on a vital force that corresponds to the illusory suction force existing in the centre of the vortex, and such vital force emerges from within the system, with no need for any other external force to produce life.
'One of the reasons why this knowledge is so important is that it ended the long-time dispute between vitalism and materialism. Vitalists defended the idea that life's existence depends on a vital force, while materialists believed that no external force was needed to produce life. [...] Vitalists quite rightly identified a vital force that corresponds to the illusory suction force existing in the centre of the vortex. The materialistic view is also correct, since such vital force emerges from the system's interior. Nothing in the exterior organises this vortex. Vital force is real, but it does not exist in the usual sense of existence, since it has what is known as hyper-existence. ${ }^{10}$

So that hyper-existence occurs, Palazzo ${ }^{10}$ adds that the system needs to meet the following conditions: the emerging phenomenon must be incorporated; the components must be unbalanced; and there must be feedback. Should these conditions occur, vortex will be manifest and the force emerging from within the system will reach the surface.

This emerging phenomenon (vortex) corresponds to the concept of force centres or chakras ('wheels' in Sanskrit) from Traditional Hindu Medicine, according to which energy vortices that are spread across the body's surface vibrate continuously and distribute vital energy or prana to the physiological systems and body components. ${ }^{3-5,17}$ According to Traditional Chinese Medicine, similar definitions and properties are attributed to the energy meridians and their respective acupoints. ${ }^{3-5,18}$ It is worth pointing out that both medical practices also present the properties of complex systems, by grounding their vitalist therapeutic approaches on the intricate network of connections comprising the force centres and energy meridians respectively. ${ }^{19-21}$

\section{Genetics, Genome and Epigenome}

The body's vital functions are fundamentally controlled by biochemical information contained in the DNA (set of nucleotide sequences) or cell genome, which passes down those characteristics to future generations and undergoes mutations that allow evolutive adaptations to different environmental factors to take place. The genome consists of exome (protein encoding DNA portion that is needed for maintaining and controlling physiological functions) and epigenome (protein non-coding DNA portion that regulates the expression of encoding genes). While exome makes up $2 \%$ of the genome, epigenome makes up the remaining $98 \%$, thus highlighting the complexity of the cell differentiation process and the resulting regulation of organic homeostasis. In 1942, British geneticist Conrad H. Waddington created the term 'epigenetics' (from the Greek prefix, epi, 'above' or 'on' genetics or classic molecular biology) to designate the control of the epigenome over the exome and respective gene expression. $^{22}$

After the fertilisation and fusion of the gametes' genetic material, the zygote replicates the same genome (exome plus epigenome) for the body's other trillion cells, influenced by internal and external signals that affect the future individual's morphology, physiology and behaviour. So that this influence reaches the cell nucleus and the genes are able to 
decode their nucleotide sequences into protein sequences, the DNA needs to be unwrapped into structures called nucleosomes. This wrapping/unwrapping process of DNA encoding regions (chromosome or chromatin remodelling) occurs by means of epigenetic mechanisms - in other words, chemical changes that occur in the DNA molecules and histone protein, among others. While the methylation of a certain DNA region usually triggers chromatin wrapping and silences the respective encoding gene, histone acetylation is often related to chromatin unwrapping and gene activation. ${ }^{23,24}$

The epigenetic alterations create a set of chemical processes that are mediated by enzymes that represent an additional mechanism of gene expression regulation at the transcriptional level, shaping how the genome works and the phenotypical profile by either activating or deactivating genes, without the occurrence of any change in the nucleotide sequence of the genetic code. ${ }^{25,26}$ The individual epigenome is passed down to the future generations ${ }^{25,27}$ following a specific epigenetic code and influencing the descendant's health-disease correlation (trans-generational epigenetic inheritance) ${ }^{28}$ By working as a highly interconnected regulating network, this epigenotype is what instructs the genome about when and where genes are to be expressed. As for an orchestra composed of several musicians, the stretches of DNA (exome plus epigenome) transcribed in each cell type act jointly, allowing one or other instrument to stand out from time to time.

In addition to being reversible, these epigenetic alterations can be expressed on the genome of individuals at any age, as long as they come in contact with internal and/or external stimuli (habits and lifestyle, pollution and radiation, medicines and hormones, inflammation, stress, emotions), ${ }^{24,25}$ activating or silencing genes that are responsible for the manifestation of a wide range of diseases. ${ }^{28-32}$

\section{Correlation of Genetics with the Paradigm of Complexity}

As creator of the term epigenetics, Waddington's intuition was that the process would consist of several concatenated, network-articulated mechanisms in a way that any earlystage modification could bring gradual but continuous modifications to the subsequent stages, thus reaching a larger number of tissues and organs, and making distinct phenotype modifications. ${ }^{33}$

Similar to the vital principle or organic vital force, the genome also presents characteristics and properties of complex and dynamic self-organisation systems, opposing the deterministic and reductionistic approach described in the paradigm of molecular biology. ${ }^{34}$

As described by Jura et al, ${ }^{35}$ advances in the epigenetics field indicate that the phenotype manifested by each individual emerges from a complex interaction between genome and the different environmental factors (epigenome). Gene expression regulation is multifactorial, and includes DNA epigenetic modification, RNA transcription, mRNA translation and many additional modifications in nascent proteins. In turn, the transcription process is highly complex, and includes hundreds of activating and silencing factors, as well as several kinds of small molecular mass RNA (microRNA). Furthermore, alternative mRNA splicing or editing can generate a polypeptide family from a single gene. DNA sequence encoding rearrangement during the somatic recombination is the source of a wide variability of proteins, which seems to take place randomly. Thus, according to its authors, the mechanism of the DNA genetic information flow sent to encoded proteins does not fit with the reductionistic and deterministic linear relationship category, and is better described by non-linear models, such as that of complex systems.

Similar to the vital force's dynamic action, studies suggest that the genome, as a non-linear, complex system, also presents the vortex as an emerging genetic informationtransmitting phenomenon among cells, ${ }^{36-39}$ since the DNA double helix structure (interlaced filaments in spiral format rotated to the right) 'generates a longitudinal wave that propagates in the direction of the magnetic field vector'. ${ }^{36}$ Thus, according to Palazzo ${ }^{10}$ and other authors, ${ }^{16}$ the very DNA mass in circular motion would animate the phenomenon, and produce a force that would emerge from the cell nucleus and convey the genetic information to every physiological system and body component.

'DNA generates a longitudinal wave that propagates in the direction of the magnetic field vector. Computed frequencies from the structure of DNA agree with those of the predicted biophoton radiation. The optimisation of efficiency by minimising the conduction losses leads to the double-helix structure of DNA. The vortex model of the magnetic scalar wave not only covers many observed structures within the nucleus perfectly, but also explains the hyperboloid channels in the matrix when two cells communicate with each other. [...] The characteristics of the potential vortex are significant. With its concentration effect, it provides for miniaturisation down to a few nanometres, which allows enormously high information density in the nucleus. [...] it becomes clear that such a wave is suitable to use genetic code chemically stored in the base pairs of the genes and electrically modulate them, so as to 'piggyback' information from the cell nucleus to another cell. At the receiving end, the reverse process takes place and the transported information is converted back into a chemical structure. The necessary energy required to power the chemical process is provided by the magnetic scalar wave itself. ${ }^{36}$

\section{Correlation between Vitalism and Genetics According to the Paradigm of Complexity}

By comparing the vital principle's overall characteristics with those of the genome (exome plus epigenome) that were described earlier, we highlighted several analogies between them, such as organic vital force and genome are the key substrates for life to emerge and be maintained (vitality of living beings). The vital principle is responsible for keeping sensations and body functions in balance, just like the genome stores biochemical information that will produce the proteins responsible for maintaining vital processes and developing organisms. Diseases occur as a result of vital force imbalance, as well as of disease-promoting genome modifications, both 
being affected by the influence of external and internal etiopathogenetic factors, among others.

When it comes to the properties of complex and dynamic systems, which correlate the modus operandi of both phenomena, the vital principle and genome present the following: substantial composition among parts or behaviour units that mutually influence one another and form a connection network that creates the complex and dynamic self-organisation behaviour; emerging phenomena. Described in both models, vortex supports the suggested correlation between vitalism and genetics, indicating the existence of a force ('vital force' or 'DNA longitudinal wave') that comes from within the organic system ('physical-vital unit' or 'cell nucleus') and is externalised as the outcome of masses in circular motion as an emergent and information-transmitting phenomenon.

In the field of anthropology, Silva and Duarte ${ }^{40}$ analyse the tensions between the vitalist and mechanist views according to many authors, concluding that, in compliance with epigenetics, 'genes perform an imaginary function that is similar to that of the vital principle', correlating the complex, dynamic and self-organisational nature of both phenomena. In the field of molecular biology, Kirschner et $\mathrm{al}^{41}$ correlate the epigenetic properties with that of vitalism, suggesting the term 'molecular vitalism' to designate the field of research on the integrative physiology between cells and organisms.

Since 1997, Khuda-Bukhsh ${ }^{42-44}$ and other authors ${ }^{45,46}$ have defended the hypothesis that homeopathic medicines act on the genome by modulating disease-promoting gene expression. In this context, dozens of experiments show that potentised homeopathic medicines act at the gene regulatory level according to three main types of effects: change in the expression pattern of many genes; cytotoxicity or apoptosis in cancer cells; therapeutic modification in gene expression. ${ }^{47}$

As implicated by the homeopathic vitalist concept, homeopathic medicines can be seen to restore the body's state of health because they modulate vital principle dystonia. By inferring that homeopathic medicines restore the body's state of health by modulating gene expression dystonia, the above experimental studies support the hypothetical correlation between genome (exome plus epigenome) and organic vital force.

\section{Conclusions}

In a recent study, ${ }^{47}$ the author developed a philosophicalscientific correlation between homeopathic chronic miasms and disease-promoting epigenetic modifications, leading to the suggested isopathic use of auto-sarcode of DNA as an antimiasmatic medicine and modulator of gene expression. In the present study, by employing the paradigm of complexity, we develop a philosophical-scientific correlation between vitalism and genetics.

By transcending the polarisation between holism and reductionism, the science of complexity allows a functional correlation (modus operandi) to be established between vital principle and cell genome, highlighting that both models consist of a network system with nodes and connections that allows the distinct parts to relate to one another, while valuing the whole and their units at the same time.
As ontological properties, organic vital force and genome can be seen to represent the substrates that are responsible for the emergence and maintenance of life, susceptibility to diseases, and the action of potentised homeopathic medicines. According to complex and dynamic self-organisation systems, both models present non-linearity, self-organisation and dynamism.

Closing the dispute between vitalism and materialism, vortex is an emerging phenomenon of complex systems that shows that both concepts are correct, according to the analytical framework: life and health depend on a vital force that corresponds to the suction force that exists at the vortex centre, which originates from within the system (substantial physicalvital unit or genome) and not as the result of any external force.

By valuing the respective fields of research addressed, it is suggested in this study that the organic vital force is able to find its biological representation in the cell genome (exome plus epigenome), while in the previous study ${ }^{47}$ it was proposed that homeopathic chronic miasms are able to find their representation in disease-promoting epigenetic modifications.

In accordance with these hypotheses, the isopathic use of auto-sarcode of $\mathrm{DNA}^{47}$ could act therapeutically on the imbalance of vital principle or genome and on the miasms or disease-promoting epigenetic modifications, through the modulation of gene expression.

\section{Highlights}

- The vital force (or vital principle) is a philosophical nonmaterial substrate, theoretically responsible for maintaining the body's sensations and functions.

- The cell genome controls the body's vital functions and consists of a protein encoding portion (exome) and another that regulates this encoding scheme (epigenome).

- Complex and dynamic self-organisation systems are composed of distinct units of behaviour that influence each other, forming an intrinsic network of connections.

- Both the vital principle and the genome (exome plus epigenome) present properties of complex and dynamic self-organisation systems.

- It is hypothesised that the cell genome is the biological representation of the organic vital force.

\section{Conflict of Interest}

None declared.

\section{References}

1 Hahnemann S. Organon der Heilkunst. Organon da arte de curar. 6th ed. Translated by Edméa Marturano Villela and Izao Carneiro Soares. Ribeirão Preto: Museu de Homeopatia Abrahão Brickmann; 1995. Available at: http://homeoint.org/books4/organon/ index.htm. Accessed April 4, 2019

2 Teixeira MZ. A concepção vitalista de Samuel Hahnemann [The vitalist concept of Samuel Hahnemann]. Rev Homeopatia (São Paulo) 1996;61:39-44

3 Teixeira MZ. O vitalismo hahnemanniano na prática clínica homeopática [Hahnemann's vitalism in homeopathic clinical practice]. Rev Homeopatia (São Paulo) 2000;65:22-34 
4 Teixeira MZ. A natureza imaterial do homem: estudo comparativo do vitalismo homeopático com as principais concepções médicas e filosóficas [The non-material nature of the man: comparative study of homeopathic vitalism with mainly medical and philosophical concepts]. São Paulo: Editorial Petrus; 2000. Available at: http://www.homeozulian.med.br/homeozulian_visualizarlivroautor.asp?id=4. Accessed April 4, 2019

5 Teixeira MZ. Antropologia Médica Vitalista: uma ampliação ao entendimento do processo de adoecimento humano [Vitalist Medical Anthropology: a broadening to the understanding of the human illness process]. Rev Med (São Paulo) 2017;96:145-158

6 Hahnemann S. The Chronic Diseases, their Peculiar Nature and their Homeopathic Cure. Dudley P, ed. Translated from the second enlarged German edition of 1835 by Prof. Louis H. Tafel. With annotations by Richard Hughes. Philadelphia: Boericke \& Tafel; 1896

7 Coffey DS. Self-organization, complexity and chaos: the new biology for medicine. Nat Med 1998;4:882-885

8 Higgins JP. Nonlinear systems in medicine. Yale J Biol Med 2002; 75:247-260

9 Bizzarri M, Palombo A, Cucina A. Theoretical aspects of systems biology. Prog Biophys Mol Biol 2013;112:33-43

10 Palazzo LA. Complexidade, caos e auto-organização [Complexity, chaos and self-organization]. In: III Oficina de Inteligência Artificial. Pelotas: Educat; 1999:49-67. Available at: http:// algol.dcc.ufla.br/ monserrat/isc/Complexidade_caos_autoorganizacao.html. Accessed April 4, 2019

11 Ramos DCS. Transdisciplinaridade em saúde: uma análise integrativa da literatura [Transdisciplinarity in health: an integrative analysis of the literature]. [Master thesis]. Universidade Estadual Paulista, Faculdade de Medicina de Botucatu; 2009. Available at: https:// repositorio.unesp.br/handle/11449/98369. Accessed April 4, 2019

12 Bell IR, Baldwin CM, Schwartz GE. Translating a nonlinear systems theory model for homeopathy into empirical tests. Altern Ther Health Med 2002;8:58-66

13 Bellavite P. Complexity science and homeopathy: a synthetic overview. Homeopathy 2003;92:203-212

14 Bellavite P, Olioso D, Marzotto M, Moratti E, Conforti A. A dynamic network model of the similia principle. Complement Ther Med 2013;21:750-761

15 Bell IR, Schwartz GE. Enhancement of adaptive biological effects by nanotechnology preparation methods in homeopathic medicines. Homeopathy 2015;104:123-138

16 Fritzsche M, Li D, Colin-York H, et al. Self-organizing actin patterns shape membrane architecture but not cell mechanics. Nat Commun 2017;8:14347

17 Sweta KM, Awasthi HH, Godbole A, Prajapati S. Physio-anatomical resemblance of inferior hypogastric plexus with Muladhara Chakra: a cadaveric study. Ayu 2017;38:7-9

18 Fromknecht R, Goncalves M, Greten HJ, Machado J. Are conduits superconductor-like and supported by tetrahedra structure of hyaluronic matrix in living systems? New perspectives. J Complement Integr Med 2013;10:259-263

19 Bell IR, Koithan M, Pincus D. Methodological implications of nonlinear dynamical systems models for whole systems of complementary and alternative medicine. Forsch Komplement Med 2012;19:15-21

20 Rioux J. A complex, nonlinear dynamic systems perspective on Ayurveda and Ayurvedic research. J Altern Complement Med 2012;18:709-718

21 Chang S. The meridian system and mechanism of acupuncture - a comparative review. Part 1: the meridian system. Taiwan J Obstet Gynecol 2012;51:506-514

22 Holliday R. Epigenetics: a historical overview. Epigenetics 2006; $1: 76-80$

23 Kouzarides T. Chromatin modifications and their function. Cell 2007;128:693-705

24 García R, Ayala PA, Perdomo SP. Epigenética: definición, bases moleculares e implicaciones en la salud y en la evolución humana
[Epigenetics: definition, molecular bases and implications in human health and evolution]. Rev Cienc Salud 2012;10:59-71

25 Costa EBO, Pacheco C. Epigenética: regulação da expressão gênica em nível transcricional e suas implicações [Epigenetics: gene expression regulation at transcriptional level and its implications]. Semina Ciências Biológicas e da Saúde 2013; 34:125-136

26 Schultz MD, He Y, Whitaker JW, et al. Human body epigenome maps reveal noncanonical DNA methylation variation. Nature 2015;523:212-216

27 Crews D, Gillette R, Scarpino SV, Manikkam M, Savenkova MI Skinner MK. Epigenetic transgenerational inheritance of altered stress responses. Proc Natl Acad Sci U S A 2012;109:9143-9148

28 Jirtle RL, Skinner MK. Environmental epigenomics and disease susceptibility. Nat Rev Genet 2007;8:253-262

29 Waggoner D. Mechanisms of disease: epigenesis. Semin Pediatr Neurol 2007;14:7-14

30 Santos-Rebouças CB, Pimentel MM. Implication of abnormal epigenetic patterns for human diseases. Eur J Hum Genet 2007; 15:10-17

31 Esteller M. Epigenetics in cancer. N Engl J Med 2008; 358:1148-1159

32 Nestler EJ, Peña CJ, Kundakovic M, Mitchell A, Akbarian S. Epigenetic basis of mental illness. Neuroscientist 2016;22:447-463

33 Freitas-Silva LR, Ortega FJG. A epigenética como nova hipótese etiológica no campo psiquiátrico contemporâneo [Epigenetics as new etiological hypothesis in the contemporary psychiatric field]. Physis: Revista de Saúde Coletiva 2014;24:765-786

34 Waliszewski P, Molski M, Konarski J. On the holistic approach in cellular and cancer biology: nonlinearity, complexity, and quasideterminism of the dynamic cellular network. J Surg Oncol 1998; 68:70-78

35 Jura J, Wegrzyn P, Jura J, Koj A. Regulatory mechanisms of gene expression: complexity with elements of deterministic chaos. Acta Biochim Pol 2006;53:1-10

36 Meyl K. DNA and cell resonance: magnetic waves enable cell communication. DNA Cell Biol 2012;31:422-426

37 Gulati S, Muller SJ, Liepmann D. Flow of DNA solutions in a microfluidic gradual contraction. Biomicrofluidics 2015; 9:054102

38 Taylor AJ, Dennis MR. Vortex knots in tangled quantum eigenfunctions. Nat Commun 2016;7:12346

39 Scheeler MW, van Rees WM, Kedia H, Kleckner D, Irvine WTM. Complete measurement of helicity and its dynamics in vortex tubes. Science 2017;357:487-491

40 Silva G, Duarte LFD. Epigênese e epigenética: as muitas vidas do vitalismo ocidental [Epigenesis and epigenetics: the sundry lives of Western vitalism]. Horiz Antropol 2016;22:425-453

41 Kirschner M, Gerhart J, Mitchison T. Molecular "vitalism". Cell 2000;100:79-88

42 Khuda-Bukhsh AR. Potentized homoeopathic drugs act through regulation of gene-expression: a hypothesis to explain their mechanism and pathways of action in vitro. Complement Ther Med 1997;5:43-46

43 Khuda-Bukhsh AR. Towards understanding molecular mechanisms of action of homeopathic drugs: an overview. Mol Cell Biochem 2003;253:339-345

44 Khuda-Bukhsh AR. Current trends in high dilution research with particular reference to gene regulatory hypothesis. Nucleus 2014; 57:3-17

45 Dei A, Bernardini S. Hormetic effects of extremely diluted solutions on gene expression. Homeopathy 2015;104:116-122

46 Bellavite P, Signorini A, Marzotto M, Moratti E, Bonafini C, Olioso D. Cell sensitivity, non-linearity and inverse effects. Homeopathy 2015;104:139-160

47 Teixeira MZ. Isopathic use of auto-sarcode of DNA as anti-miasmatic homeopathic medicine and modulator of gene expression? Homeopathy 2019;108:139-148 